ORIGINAL ARTICLE

\title{
Frequency of Urinary Tract Infection in Children with Diarrhea
}

\author{
ALI AKBAR ${ }^{1}$, ABDUL MOEED KHAN², ASADULLAH KHAN ${ }^{3}$, FARHANA AHMAD ${ }^{4}$, MUHAMMAD AKRAM ${ }^{5}$, ALLAH NAWAZ \\ SULTAN6 \\ 1,2FCPS Pediatrics, Fellow Pediatric Cardiology Lady Reading Hospital Peshawar \\ ${ }^{3}$ Specialist Paediatrician Alkhidmat Hospital, Peshawar \\ ${ }^{4}$ Assistant Professor Pediatrics, Central Park Medical College, Lahore \\ ${ }^{5}$ Assistant Professor Pediatrics, Sharif Medical and Dental College, Lahore \\ ${ }^{6}$ Assistant Professor Pediatrics, Sharif Medical and Dental College, Lahore \\ Corresponding author: Dr. Asadullah Khan, drasadghalib90@gmail.com, Cell No.+923129441135
}

\begin{abstract}
Aim: To determine the frequency of UTI in children presented with diarrhea.

Study Design: Cross-sectional

Place and Duration: Pediatrics department of Alkhidmat Hospital, Peshawar and Sharif Medical and Dental College, Lahore for six months duration from October 2020 to March 2021.

Methodology: Total 120 patients of both gender with ages 2 months to 5 years were enrolled in this study. After taking written consent from parents/guardians, detailed demographics including age, sex, residence, severity and complete medical history were examined and recorded. Urine samples were obtained for examination of urine culture. Data was analyzed by SPSS 24.0 .

Results: There were $78(65 \%)$ males while $42(35 \%)$ patients were females. $58(48.33 \%)$ patients were ages $<1$ years, $45(37.5 \%)$ had ages between 1 to 3 years and $17(14.17 \%)$ were ages of $>3$ years. $36(30 \%)$ patients had mild, $50(41.67 \%)$ had moderate and $34(28.33 \%)$ had severe diarrhea. UTI was found in $40(33.33 \%)$ patients. E.coli was the commonest organism found in $28(70 \%)$ patients followed by K. pneumonia in $12(30 \%)$ patients. Conclusion: Frequency of urinary tract infection was high among children with diarrhea. E.coli was the commonest organism associated with UTI.
\end{abstract}

Keywords: Urinary Tract Infection, Diarrhea, Children

\section{INTRODUCTION}

Urinary tract infection (UTI) is the second most frequent bacterial cause in infants and children with diarrhea [1]. Among younger children with UTI, diarrhoea may be a presenting symptom $[2,3]$.

In pediatrics, urinary tract infection (UTI) is still the most frequent cause of febrile illness [4]. Aside from gastrointestinal and respiratory tract infections, it is the third most frequent bacterial illness among children in poor nations. Some host variables, including obstructive uropathy, urolithiasis, inadequate emptying of the bladder with residual urine, noncircumcision in males, female sexual activity beyond infancy, and constipation, increase the risk of UTI in children [5-6]. To counteract bacterial adherence to the urinary tract lining, several host defensive mechanisms exist, including the intrinsic defense of the bladder epithelial cells, secretory immunoglobulin A $(\lg A)$ in urine, and blood type antigens in secretions [7].

Early in childhood, boys are more vulnerable to UTIs than females. The incidence of UTI was reported to be 20 percent in males who had not had circumcision, and 5 percent in girls [8]. Girls, on the other hand, are more likely to be affected later in life. There is an $8.1 \%$ incidence in females and a 1.9 percent incidence in boys between the ages of 2 and 4 years. However, symptomatic urinary tract infection is more frequent in females after the first year [9].

Parenteral diarrhea is a kind of diarrhoea whose origin is external to the gastrointestinal system. Meningitis, otitis media, and urinary tract infections (UTIs) may cause diarrhea, as can systemic illnesses. Many individuals in Pakistan, particularly babies, have been afflicted by this illness, which is one of the most deadly and has killed thousands of people over the course of the year in
Pakistan. Children and babies with diarrhea were included in the research.

\section{MATERIALS AND METHODS}

This cross-sectional study was conducted at Pediatrics department of Alkhidmat Hospital Peshawar and Sharif Medical and Dental College, Lahorefor six months duration from October 2020 to March 2021. In this study total 120 patients of both gender with ages 2 months to 5 years were enrolled in this study. After taking written consent from parents/guardians, detailed demographics including age, sex, residence, severity and complete medical history were examined and recorded. Patients with history of antibiotics use within 48 hours, children above 5 years of age and those with no consent were excluded from this study.

Urine culture was examined by urinary catheterization method. Urine was sent for the culture to a reliable lab and signs and symptoms of all the patients were noted. Patient management was done with standardized techniques. All the data was analyzed by SPSS 24.0. Mean \pm SD was obtained. Frequency and percentages were recorded in tabulation form.

\section{RESULTS}

Out of 120 patients, $78(65 \%)$ males while $42(35 \%)$ patients were females. $58(48.33 \%)$ patients were ages $<1$ years, $45(37.5 \%)$ had ages between 1 to 3 years and 17 $(14.17 \%)$ were ages of $>3$ years. $36(30 \%)$ patients had mild, $50(41.67 \%)$ had moderate and $34(28.33 \%)$ had severe diarrhea. $55(45.83 \%)$ patients had rural residency while $65(54.17 \%)$ had urban residency. (Table 1 ) 
Table No 1: Demographics of all the included patients

\begin{tabular}{|l|l|l|}
\hline Characteristics & Frequency No. & \%age \\
\hline Age (years) & 58 & $48.33 \%$ \\
\hline$<1$ & 45 & $37.50 \%$ \\
\hline 1 to 3 & 17 & $14.17 \%$ \\
\hline$>3$ to 5 & 78 & $65 \%$ \\
\hline Gender & 42 & $35 \%$ \\
\hline Male & 65 & $54.17 \%$ \\
\hline Female & 65 & $45.83 \%$ \\
\hline Residence & 55 & $30 \%$ \\
\hline Urban & 36 & $41.67 \%$ \\
\hline Rural & 50 & $28.33 \%$ \\
\hline Severity & 34 & \\
\hline Mild &
\end{tabular}

Culture proven UTI was found in 40 (33.33\%) patients while $80(66.67 \%)$ patients had no UTI. (Figure 1)

Figure No 1: Frequency of UTI among all the patients

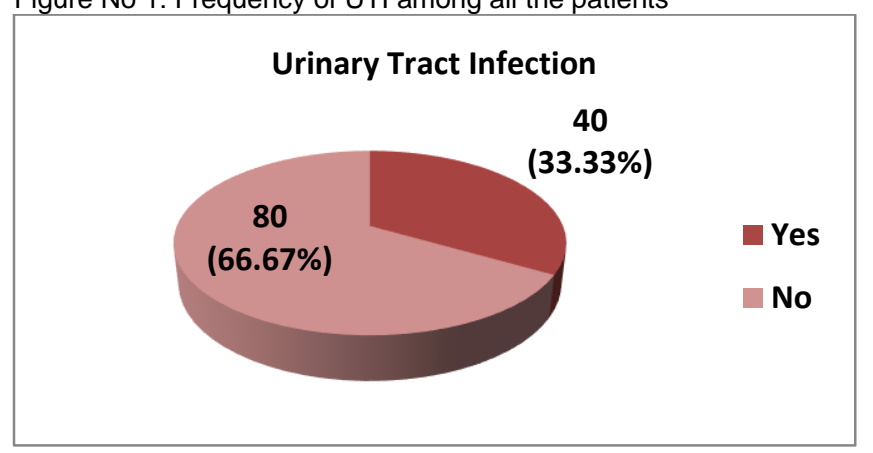

E.coli was the commonest organism found in 28 (70\%) patients followed by K. pneumonia in 12 (30\%) patients. (Table 2)

Table No 2: Organisms associated with UTI $(n=40)$

\begin{tabular}{|l|l|l|}
\hline Organisms & Frequency No. & $\%$ age \\
\hline E. Coli & 28 & $70 \%$ \\
\hline K. Pneumoniae & 12 & $30 \%$ \\
\hline
\end{tabular}

\section{DISCUSSION}

Worldwide, diarrhea is the most common disease in infants/children. It is commonly found in children with ages $<5$ years and associated with increased rate of morbidity and mortality [10]. Urinary tract infection is the frequently found complication associated with diarrhea and many of studies reported that UTI was the commonest cause of diarrhea and acute gastroenteritis in children with agesupto 5 years [11-12]. In this study 120 children of diarrhea were examined for culture proven UTI. $78(65 \%)$ males while 42 (35\%) patients were females. $58(48.33 \%)$ patients were ages $<1$ years, $45(37.5 \%)$ had ages between 1 to 3 years and $17(14.17 \%)$ were ages of $>3$ years. These results were comparable to some previous studies in which male children were high in numbers and accounted more than $60 \%$ and majority of children were of ages $<1$ year [13-14].

In present study we found that $36(30 \%)$ patients had mild, 50 (41.67\%) had moderate and 34 (28.33\%) had severe diarrhea. A study conducted by Saeedi $F$ et al [15] reported that $40 \%$ children had moderate, $46.7 \%$ had mild and $13.3 \%$ had moderate diarrhea. In our study culture proven UTI was found in $40(33.33 \%)$ patients while 80 (66.67\%) patients had no UTI. Saeedi F et al [15] reported that $15(7.5 \%)$ patients had UTI out of 200 diarrhea patients.

The incidence of UTI in infants ranges from $0.1 \%$ to $1.0 \%$ in newborn infants to as high as $10 \%$ in low-birthweight infants. The most common presenting symptoms in young children are fever, vomiting or diarrhea, irritability or fussiness, poor feeding, and poor weight gain [16]. In children older than 2 years of age, the presenting complaints of UTIs are pain or burning when urinating, frequent need to urinate, pain in the lower abdomen or over the sides of the back, and fever.

J.M Afridi et al [17] reported that out of 88 diarrhea patients they found $27(30.68 \%)$ patients had urinary tract infection. Another study by Ahmad $\mathrm{N}$ et al [18] regarding prevalence of UTI in children with diarrhea, in their study, they examined 200 children and out of which 60 (30\%) had culture proven Urinary tract Infection. Escherichia Coli, Proteus, Pseudomonas Aeruginosa and Citrobacter were the most commonly isolated organisms seen on the culture report. Our study showed similar findings regarding isolated organisms as reported by J.M Afridi and Ahmad $\mathrm{N}$ et al [1718].

In our study we found that E.coli was the commonest organism in $28(70 \%)$ patients followed by K. pneumonia in $12(30 \%)$ patients. Many of previous studies reported that E. Coli was the most frequent organism associated with urinary tract infection [19-20].

Approximately 2.5 million people die due to diarrhea. $65-75 \%$ of these are the children less than five years. Diarrhea due to parenteral cause may be due to UTI which mimics systemic infection. Diarrhea is most commonly seen in children associated with UTI but the etiology, risk factors have not been studies very well even until now.

\section{CONCLUSION}

Diarrhea is the most common disease in infants/children. It is commonly found in children with ages $<5$ years and associated with increased rate of morbidity and mortality. Urinary tract infection is the frequently found complication associated with diarrhea and many of studies reported that UTI was the commonest cause of diarrhea. We concluded from this study that frequency of urinary tract infection was high among children with diarrhea. E.coli was the commonest organism associated with UTI.

\section{REFERENCES}

1. Synder HM. Urologic emergencies. In: Fleisher GR, Ludwig $\mathrm{S}$, eds. Textbook of pediatric emergency medicine, 4th ed. Baltimore, Lippincott, Williams \& Wilkins, 2000:1585-93.

2. Shaw $\mathrm{KN}$, Gorelick $\mathrm{MH}$. Urinary tract infection in the pediatric patient. Pedia atric clinics of North America, 1999, 46(6):1111-23.

3. Dairiki Shortliffe LM. Urinary tract infect tions in infants and children. In: Walsh PC et al. Campbell's urology, 8th ed. Philad delphia, WB Saunders, 2002:1846-84.

4. Shaikh N, Morone NE, Bost JE, Farrell MH. Prevalence of urinary tract infection in childhood: a meta-analysis. Pediatr Infect Dis J. 2008;27(4):302.

5. Chang SL, Shortliffe LD. Pediatric urinary tract infections. Pediatr Clin North Am. 2006;53(3):379-400. 
6. Srivastava RN, Bagga A. Urinary tract infection. In: Srivastava RN, Bagga A, editors. Pediatric Nephrology. 4th ed. New Delhi: Jaypee; 2005:235-26.

7. Stein R, Dogan HS, Hoebeke P, Kočvara R, Nijman RJ Radmayr C, et al. Urinary tract infections in children: EAU/ESPU guidelines. Eur Urol 2015;67:546-58.

8. Elder, J 2015, 'Urinary tract infection', in R Behrman, R Kliegman, $\mathrm{H}$ Jenson (eds.), Nelson Textbook of Pediatrics, WB Saunders Company, Philadephia,

9. Narayanappa, D, Rajani, H \& Sangameshwaran, A 2015, 'Study of Urinary Tract Infection in Infants and Young Children with Acute Diarrhea', Ind J Publ Health Res Develop, vol 6, no. 2.

10. World Health Organization. Diarrhea. [online] Available from: who.int/ health-topics/diarrhoeal.htm. [Accessed July, 2013].

11. Ladomenou F. Bitsori M. Galanakis E. Incidence and morbidity of urinary tract infection in a prospective cohort of children. Acta Paediatrica, International Journal of Paediatrics. 2015; 104: e324-e329

12. Shaikh N. Hoberman A. Keren R. Ivanova A. Gotman N. Chesney R.W. et al. Predictors of antimicrobial resistance among pathogens causing urinary tract infection in children. J Pediatr. 2016; 171: 116-121

13. Uwaezuoke SN. The prevalence of urinary tract infection in children with severe acute malnutrition: a narrative review. Pediatric Health Med Ther. 2016;7:121-127
14. O'Brien, K, Stanton, N, Edwards, A, Hood, K \& Butler, C 2011, 'Prevalence of urinary tract infection (UTI) in sequential acutely unwell children presenting in primary care: exploratory study', Scand J Prim Health Care, vol 29, pp. 19-22.

15. Saeedi F, Malekzadeh I, Moghtaderi M. Urinary tract infections in children presenting with acute gastroenteritis. Asian J Pediatr Nephrol 2021;4:19-21

16. Thakar, R, Rath, B, Prakash, K, Mittal, S \& Talukdar, B 2000, 'Urinary tract infection in infants andyoung children with diarrhoea', Ind Pediatr, vol 37, pp. 886-89.

17. Afridi, J.M. \& Amir, Safa \& Rehman, Y. \& Rahim, Fakher (2018). Urinary tract infection as a cause of parenteral diarrhea in children. Medical Forum Monthly. 29. 11-14.

18. Nabeel Ahmad, Maryam Farooq and Hassan Farooq. Urinary Tract Infection and its association with Parenteral Diarrhea in Children. AJMS; 7(4) April, 2019.

19. Nibhanipudi KV. A Study to Determine the Incidence of Urinary Tract Infections in Infants and Children Ages 4 Months to 6 Years With Febrile Diarrhea. Glob Pediatr Health. 2016;3:2333794X16667175. Published 2016 Sep 12. doi:10.1177/2333794X16667175

20. Alberici I. Bayazit A.K. Drozdz D. Emre S. Fischbach M. Harambat J. et al. Pathogens causing urinary tract infections in infants: a European overview by the ESCAPE study group. Eur J Pediatr. 2015; 174: 783-790 